Article

\title{
Achieving Carbon Neutrality for A Future Large Greenhouse Gas Emitter in Quebec, Canada: A Case Study
}

\author{
Patrick Faubert ${ }^{1, *,+}{ }^{+}$, Sylvie Bouchard ${ }^{1,+}$, Rémi Morin Chassé ${ }^{1,2}$, Hélène Côté ${ }^{1}$, \\ Pierre-Luc Dessureault ${ }^{1}$ and Claude Villeneuve ${ }^{1}$ \\ 1 Chaire en Éco-Conseil, Département des Sciences Fondamentales, Université du Québec à Chicoutimi, \\ 555 Boulevard de 1'Université, Chicoutimi, QC G7H 2B1, Canada; sylvie1_bouchard@uqac.ca (S.B.); \\ remi_morinchasse@uqac.ca (R.M.C.); helene.cote4@uqac.ca (H.C.); pierre-luc_dessureault@uqac.ca (P.-L.D.); \\ claude_villeneuve@uqac.ca (C.V.) \\ 2 Département des Sciences Économiques et Administratives, Université du Québec à Chicoutimi, \\ 555 Boulevard de l'Université, Chicoutimi, QC G7H 2B1, Canada \\ * Correspondence: patrick1_faubert@uqac.ca; Tel.: +1-418-545-5011 \\ + These authors contributed equally to this work.
}

Received: 28 May 2020; Accepted: 29 July 2020; Published: 31 July 2020

\begin{abstract}
To reach the Paris Agreement targets of holding the global temperature increase below $2{ }^{\circ} \mathrm{C}$ above the preindustrial levels, every human activity will need to be carbon neutral by 2050 . Feasible means for industries to achieve carbon neutrality must be developed and assessed economically. Herein we present a case study on available solutions to achieve net-zero carbon from the get-go for a planned liquefied natural gas (LNG) plant in Quebec, which would classify as a large Canadian greenhouse gas (GHG) emitter. From a literature review, available options were prioritized with the promoter. Each prioritized potential solution is discussed in light of its feasibility and the associated economic opportunities and challenges. Although net-zero carbon is feasible from the get-go, results show that the promoter should identify opportunities to reduce as much as possible emissions at source, cooperate with other industries for $\mathrm{CO}_{2}$ capture and utilization, replace natural gas from fossil sources by renewable sources and offset the remaining emissions by planting trees and/or buying offsets on the compliance and voluntary markets. As some of these solutions are still to be developed, to ensure timely net-zero pledge for the lifespan of the LNG plant, a portfolio and progressive approach to combine offsets and other options is preferable.
\end{abstract}

Keywords: carbon neutral; zero carbon; GHG source reduction; offset credit; large emitter

\section{Introduction}

Climate change induced by anthropogenic activities is one of the most challenging global environmental issues the international community has faced over the last 40 years. The Paris Agreement (in effect as of November 2016) invites countries to implement measures aiming at keeping the global temperature rise by 2100 , well below $2{ }^{\circ} \mathrm{C}$ above pre-industrial levels and further restrain the temperature increase to $1.5^{\circ} \mathrm{C}$ [1]. In 2018, the Intergovernmental Panel on Climate Change (IPCC) published a special report [2] on the mitigation of climate change. The report finds that limiting global warming to $1.5^{\circ} \mathrm{C}$ calls for a transformation of the global economy and the swift implementation of drastic actions leading to a drop of the net anthropogenic emissions of circa $45 \%$ of the 2010 reference level by 2030, so as to reach "net-zero" by 2050. Although the actual estimates point to an increase in global temperature of $>1.5^{\circ} \mathrm{C}$, the means to curtail climate change are there but require unprecedented changes worldwide [2-4]. 
The energy industry, due to fossil fuels consumption, is one of the economic sectors having the greatest impact on climate change [2], and therefore, efforts to move towards renewable energy supplies should be optimized worldwide [5-7]. Transition enticed greenhouse gas (GHG) emissions reductions are key but must be accompanied by a wide array of mitigation options, and investments in both strategies must be significantly increased $[2,8]$.

In response, various groups of willing banks, companies and industries are associating, adopting policies and initiatives to decarbonize the economy [3,9-17]. The United Nations (UN) global compact is such an example where companies are invited to commit to the UN's Sustainable Development Goals (SDGs) notably in terms of GHG emissions and to set science-based targets (see [18]) in alignment with the $1.5^{\circ} \mathrm{C}$ pathways, reaching net-zero emissions by 2050 [15]. Carbon neutrality or net-zero emissions entails that all anthropogenic GHG emissions, within a defined boundary (e.g., a building, a company, a city, a government, a country), are accounted for, reduced as much as possible and, as a last resort, balanced by carbon removal or offsets [2]. Therefore, every new source of GHG emissions hampers the chances for success of the Paris Agreement.

To achieve a global net-zero carbon footprint by 2050, any new GHG producing activity or industry should be carbon neutral from the beginning, reducing the pressure on an already challenged system $[17,19-24]$. New industrials wishing to abide by this rule often lack the understanding and knowledge of the scientific principles, rules and various regulations in effect, necessary to establish their potential carbon footprint and the means to erase it. Therefore, knowledge is scarce on the practical way to achieve this target from the get-go. We here present a case study of a potential future liquefied natural gas (LNG) plant to be built and operate in the Saguenay-Lac-St-Jean area, Quebec, Canada. The goal of the study was to determine if and how such a plant, as a predictable large Canadian GHG emitter, can be carbon neutral, outweighing each potential solution in terms of practicality and economic feasibility.

\section{Materials and Methods}

\subsection{The Case Study}

GNL Québec is a Quebec, Canada-based company in the LNG field, aiming to build and operate a natural gas liquefaction complex (project Énergie Saguenay, [25]) in the Grande-Anse, Saguenay port facilities (Figure 1). The plant, connected to Quebec's hydroelectric power grid, should include liquefaction equipment, storage facilities and marine shipment infrastructures. As the natural gas supply is sourced from western Canada, a new $\sim 780 \mathrm{~km}$ long pipeline (under the responsibility of Gazoduq, inc., Montreal, Canada) is required to link the facility to the existing main gas pipeline system in Ontario [26]. The company expects to export 11 million tons of LNG per year offering transition energy of lower carbon footprint than fuel oils and coal to the European and Asian markets [25,27,28]. GNL Québec also aims for its liquefaction facility to be carbon neutral from the get-go, i.e., at the anticipated beginning of its operations in 2025 and for the duration of its operations [25]. In 2019, an environmental impact statement $[27,28]$ comprising a life-cycle analysis (LCA) was performed by specialized third parties to meet both federal (Canada) and provincial (Quebec) governmental pre-approval assessment requirements. The process for the environmental impact assessment is currently in phase $3[29,30]$. 


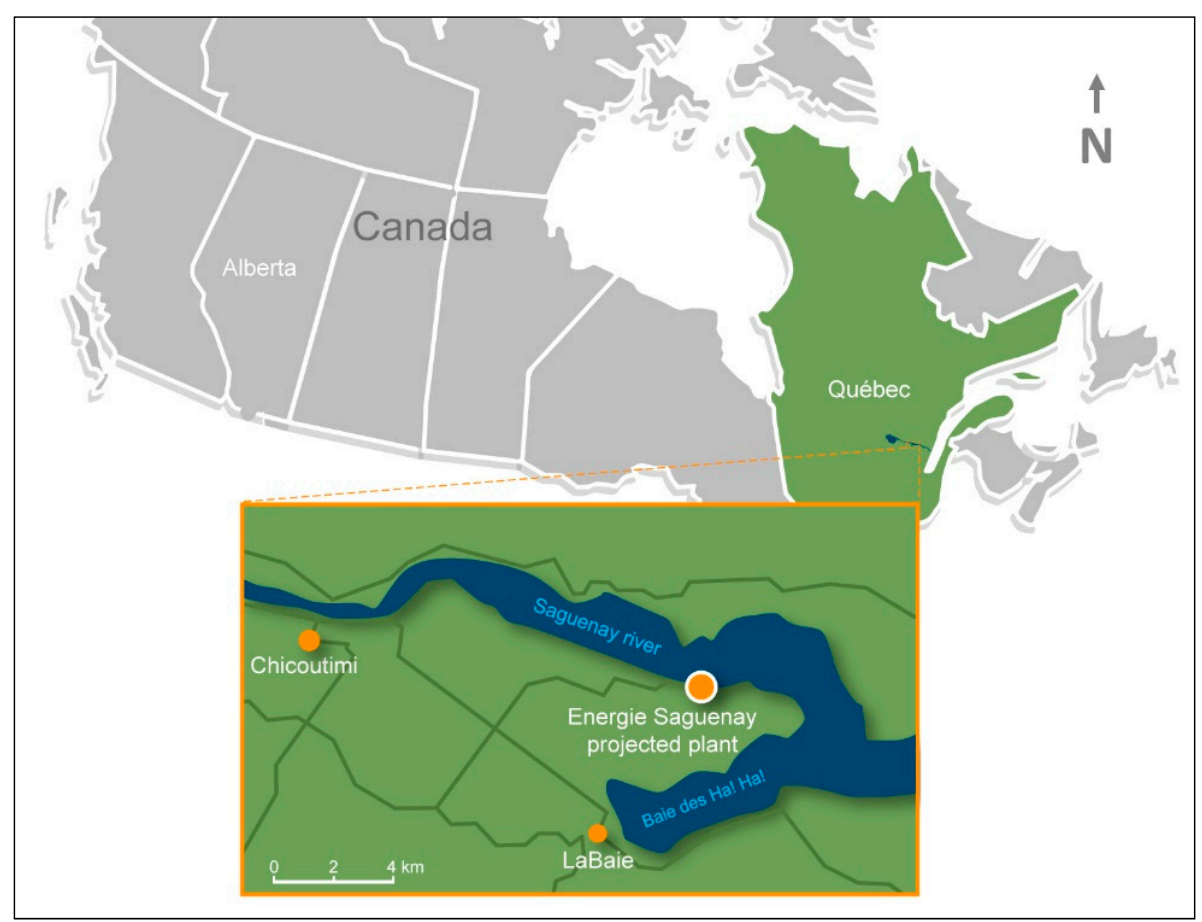

Figure 1. Location of the proposed site for the natural gas liquefaction complex of the project Énergie Saguenay, GNL Québec (Saguenay, Quebec, Canada).

In Quebec, the Cap-and-Trade System (Système québécois de plafonnement et d'échange de droits d'émission; SPEDE), a compliance carbon market linked in 2014 to the Californian system within the Western Climate Initiative (WCI) framework, mandates that industrial emitters responsible for $>25,000 \mathrm{tCO}_{2}$-eq $\mathrm{y}^{-1}$ offset all emissions above their allocated GHG emission units [31,32]. In accordance with Quebec's SPEDE's regulations, only direct GHG emissions-Scope 1 of the Énergie Saguenay project, i.e., the ones directly linked to the liquefaction facility activities per se are to be considered [32,33]. Emissions relating to natural gas extraction and transport are to be taken stock of and reported to the pertinent provincial ministry by the extracting company and pipeline owners, respectively [32,33]. Hydroelectricity provided to the plant by Hydro-Québec (crown corporation) falls into their own Scope 1 emission declaration to the SPEDE and are excluded from the Energie Saguenay project GHG balance sheet to avoid double-entry [32,33]. Therefore, the organizational boundaries are circumscribed to the liquefaction complex and the reductions and/or offsets must match the pertaining future emissions, estimated in the LCA to be $421,000 \mathrm{tCO}_{2}-\mathrm{eq} \mathrm{y} \mathrm{y}^{-1}\left(420,000 \mathrm{tCO}_{2} \mathrm{y}^{-1}\right.$ and $1000 \mathrm{tCO}_{2}$-eq $\mathrm{y}^{-1}$ due to methane- $\left.-\mathrm{CH}_{4}\right)[27,32]$.

\subsection{Methodology}

To establish which credible means are available for the Énergie Saguenay project to be carbon neutral, a literature review was first performed. The aim of the literature review was to identify mitigation solutions available to industrials worldly, either as a potential for source reduction, substitution or offsets. The literature review identified mitigation solutions for the economic sectors of energy, agriculture, forestry, buildings, transport, industry as well as in geoengineering. Therefore, the aim was to present a wide perspective of solutions in order to allow and assist the promoter in selecting and prioritizing options adapted to its context. In this perspective, the method used to search for relevant material included qualitative and quantitative approaches. Peer-reviewed literature was searched from Scopus and Web of Science databases. The selection criteria of the iterative search were specified to extract literature reviews published between 2015 and 2019 in order to use the most recent research on the identified topics. Search strategy used first general terms: $\left(\mathrm{CO}_{2}\right.$ or 
"carbon dioxide" or CO(sub2) or "greenhouse gas" or "greenhouse gases" or GHG) and (capture or sequestration or management or mitigation or reduction or offset or offset* or compensation or storage) and (application* or technolog* or solution*) and type=review and 2015-2019 and la=English. The second step was to extract articles from the first search from the domains of biological sequestration ("biological sequestration" or "biological carbon sequestration" or soil or soils or grassland* or forest* or peatland* or algae or algal or enzym*), geological sequestration ("geological sequestration" or "carbon capture and storage" or "carbon dioxide capture and storage" or " $\mathrm{CO}_{2}$ capture and storage" or CCS or "carbon sequestration" or "underground injection" or "mineral sequestration" or "carbon capture and utili*ation" or CCU) and others, including geoengineering (geoengineer* or "planetary engineering" or terraform* or "climate engineering" or "climate remediation" or "climate intervention" or "atmospheric greenhouse removal" or "negative emissions technolog*"). All the articles were finally categorized based on their economic sector. Other peer-reviewed articles were also included based on their relevance to the identified topics and were not limited to a timeframe. Moreover, material from grey literature from recognized international organisms and other institutions (e.g., reports) was added when it was relevant with the topics. The outputs of this literature review are detailed and presented in the supplementary materials (Tables S1-S7).

Based on all the mitigation solutions found in the literature review and on the understanding of what a future LNG plant located in the Saguenay-Lac-St-Jean area involves, four more probable and applicable solutions were selected and prioritized with the promoter and further analyzed. Selection and prioritization were based on the context of the promoter regarding its location (e.g., access to feedstock and energy sources), social acceptability (e.g., offset quality-ex-post vs. ex-ante-and will to participate to local economy) and accessibility to local markets. Each was regarded in terms of its feasibility (technological maturity) and economic viability, concentrating on the challenges and opportunities it may represent. These selection criteria were chosen in order to achieve the pledge from the get-go for the lifespan of the LNG plant. Literature found for each solution as well as on the economic feasibility is detailed and presented in the supplementary materials (Tables S3 and S8-S10).

\section{Results and Discussion}

\subsection{GHG Mitigation Solutions Available Worldwide: Outputs from the Literature Review}

The literature review on worldly potential mitigation solutions resulted in a total of 239 relevant documents from the sectors of agriculture (26\%), energy (21\%), forestry $(19 \%)$, geoengineering $(14 \%)$, transport (11\%), buildings (5\%) and industry (4\%) (Figure 2; Tables S1-S7). The lowest number of documents in the building (12) and industry (10) sectors is not a worry as these studies were mostly literature reviews and reports of various sources. All together, these mitigation solutions provide enough opportunities to reduce and capture GHG worldwide to achieve the $-45 \%$ decrease by the 2030 objective $[2,8]$. 


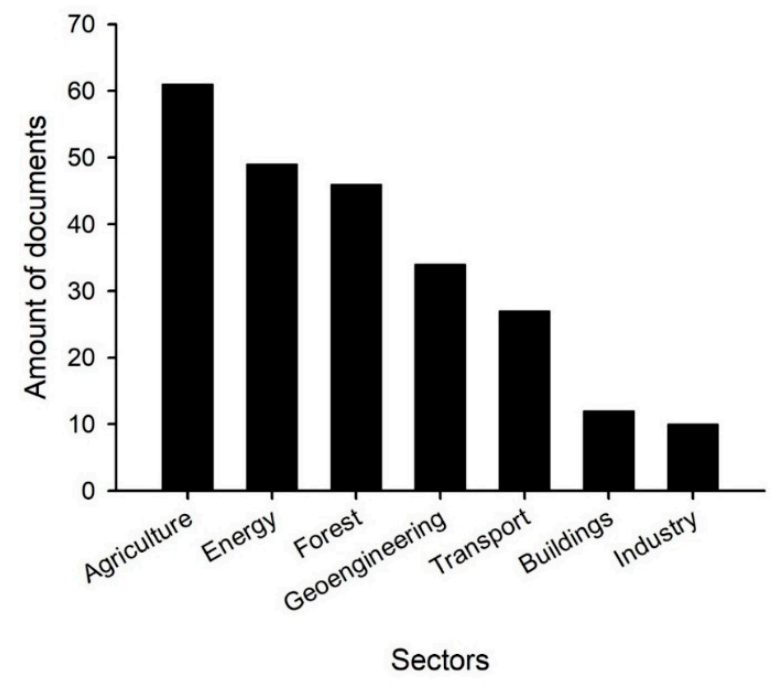

Figure 2. Amounts of relevant documents found in the literature review performed on credible means to reduce greenhouse gas emissions and to identify mitigation solutions available to industries globally, either as a potential for source reduction, substitution or offsets.

\subsection{Potential Solutions for the Énergie Saguenay Project to Be Carbon Neutral}

There are several solutions to achieve carbon neutrality for an industry and possibilities increase when GHG reductions and/or substitutions can be planned ahead of construction, relevant technology and potential synergies with other industrials being integrated in the projected plant's design, leaving offsetting options as the last resort. In the case of the Énergie Saguenay project, building and operating a LNG facility using hydroelectricity, a renewable energy, considerably lowers the carbon footprint of the LNG produced compared with a conventional LNG plant where the business as usual mode is to produce cooling and electricity with gas turbines $\left(0.022 \mathrm{~kg} \mathrm{CO}_{2}\right.$-eq $\mathrm{kWh}^{-1}$ for hydroelectricity compared to $0.685 \mathrm{~kg} \mathrm{CO}_{2}$-eq $\mathrm{kWh}^{-1}$ for high voltage electricity from natural gas) [27,34]. However, in the case of the Énergie Saguenay project, supplied electricity are Scope 2 GHG emissions [33], which are outside of the project's boundaries; therefore, other means of achieving net-zero emissions must be used.

The four potential solutions to achieve carbon neutrality of the Énergie Saguenay project are presented and discussed in the following sections in terms of practicality and economic feasibility. Two of these solutions concern GHG reductions with $\mathrm{CO}_{2}$ utilization and waste heat recovery as well as the substitution of natural gas from fossil sources with renewable natural gas from biogenic sources. The two remaining solutions consist of offsets by afforestation and carbon credits from the compliance and voluntary carbon markets.

\subsection{1. $\mathrm{CO}_{2}$ Utilization and Waste Heat Recovery}

The Énergie Saguenay project expects to produce $420,000 \mathrm{t} \mathrm{CO}_{2} \mathrm{y}^{-1}$ as part of their process to purify the natural gas and remove traces of water, $\mathrm{H}_{2} \mathrm{~S}$ and $\mathrm{CO}_{2}$ that could damage the liquefaction equipment during cooling, as well as from the natural gas vapors, usually flared [27]. Looking at this $\mathrm{CO}_{2}$ as a byproduct from an industrial ecology standpoint, it represents an opportunity for the company as it falls in the new innovative field of carbon capture and utilization (CCU) (Table S8). CCU is one of the promising solutions to mitigate global warming $[2,35,36]$ and the field is fast advancing, particularly in the development of new technology to utilize flue gas emissions [35,37-39]. There are numerous reviews, entire journals even, dedicated to the potential of CCU in the available pathways (direct use, mineralization, biological and chemical conversion) (Table S8).

Potential outputs for recovered $\mathrm{CO}_{2}$ waste in the Énergie Saguenay project can be analyzed in terms of technology readiness level, cost effectiveness and available markets, but environmental and 
GHG impacts also need to be addressed $[9,38,39]$. Finding local markets and distributing the $\mathrm{CO}_{2}$ to third parties for recovery would benefit GNL Québec and its potential clients both economically and in its net-zero objective as the recovered $\mathrm{CO}_{2}$ would be removed from its GHG annual declaration [32,40].

In addition to $\mathrm{CO}_{2}$ recovery, waste heat (WHE) generated by the plant's operations can also be recovered and used within the facility or by third parties. Industrial waste heat recovery is another fast-evolving field (Table S8) with companies emerging to aid in the assessment of potential sources, available technology and economically sound solutions (the Canadian government bears a similar initiative [41]). As for the $\mathrm{CO}_{2}$, there are many possible outputs for WHE, especially in industrial processes with high heat demand (Table S8). At least two avenues allow to combine both residual heat and $\mathrm{CO}_{2}$, i.e., commercial greenhouses or algae cultivation (as fertilizers, biofuels or proteins, for example) [36]. In a carbon neutrality context, GNL Québec or the third party replaces or reduces its fossil fuel consumption by using WHE, carbon credits can be obtained if valid methodologies and protocols are strictly followed and credits' ownership is negotiated (otherwise they would solely apply to the third party) $[1,33,42-44]$.

The plant design should include some flexibility to facilitate the installation of CCU and waste heat recovery technology in the future [45]. This would lower the discounted cost of retrofits [46] and give the firm the choice of integrating more suitable technology as they appear.

Market-related features of this option are the main unknowns. Few data on $\mathrm{CO}_{2}$ prices are publicly available. Published price estimates are on the high side [47], but cost estimates vary widely [48]. The relevance of this option for the Énergie Saguenay project also depends on the provincial $\mathrm{CO}_{2}$ market dynamics and features. The industrial gas market is a highly concentrated industry worldwide [49] and the local market dynamics are likely to be the same. Pursuing this option may require partnering with an existing player. On a positive note, with both CCU and waste heat recovery technology, a marketable end-product can help pay back the initial fixed costs and achieve carbon neutrality at a lower cost.

\subsubsection{Renewable Natural Gas (RNG)}

Natural gas to be liquefied at the Énergie Saguenay facility are projected to originate from fossil sources in Western Canada [27,28]. According to the performed LCA for the Énergie Saguenay project, which includes upstream emissions due to the natural gas life cycle and excludes downstream transport and final use, $91 \%$ of the expected GHG emissions (7858 $\mathrm{kt} \mathrm{CO}_{2}-\mathrm{eq} \mathrm{y}^{-1}$ ) are linked to the natural gas sourcing and transport to the LNG plant [50]. The GHG life cycle impact of the project can therefore be greatly affected and reduced by using, at least partially, natural gas produced from renewable sources [51]. As for Scope 1 Énergie Saguenay emissions resulting from RNG will be discounted as biogenic $\mathrm{CO}_{2}$ is not considered in Quebec SPEDE. Biomethanisation (first generation technology), pyrolysis followed by a gasification (second generation) and pyrocatalytic hydrogenation ( $\mathrm{PCH}$, second generation) appears to be the most feasible mean to produce RNG (Table S9). Because of the plant's location in Quebec's boreal forest under exploitation, local biomass, namely logging residue, are of particular interest as feedstock for RNG [52,53]. Both pyrolysis with gasification and PCH can use this feedstock and are emergent technology operated at pilot scales (the first being tested locally in the Saguenay-Lac-St-Jean area to mainly produce biochar) with a potential to peak in 2030 [54-56]. Logging residue potential RNG yield has been estimated at 3089.3 million cubic meters for the Province of Quebec by that year [54].

By substituting part of its natural gas supply by RNG, GNL Québec could in theory generate carbon credits to reduce Énergie Saguenay's carbon footprint and meet governmental GHG reduction requirements. However, the SPEDE does not currently have a corresponding approved methodology, unlike the regulated carbon markets of Alberta and British Columbia [31,57-59]. Quebec's government has regulated nonetheless that natural gas suppliers should include 1\% of RNG in 2020, $\%$ in 2023 and at least $5 \%$ by 2025 to notably stimulate technological advancements to use forestry biomass as feedstock [60]. It is not clear if Énergie Saguenay will have to comply with this regulation bylaw, 
as they do not distribute natural gas in Quebec and planned customers are overseas. Carbon credits to be generated by RNG substitution will therefore in the worst case have to go above these mandatory thresholds and will have to be traded either on voluntary markets (or Alberta and British Columbia markets as voluntary participants) or claimed by clients on other markets. As each credit is serialized and unique, if the Énergie Saguenay project was to use the RNG credits to achieve carbon neutrality, then their buyers overseas could not use them to reduce their own footprints. As $\mathrm{CO}_{2}$ extracted from the flue biogas is biogenic, it will proportionately reduce the plant accounted emissions by the same magnitude.

To operationalize the RNG option, an entire sub-industry has to be created, which, by itself, comes with risk. The inputs are a by-product of logging activities, which have been somewhat volatile over the last 30 years [61]. If RNG generation is outsourced, local business partners must be found to profitably generate and transport the gas, the value of the serialized credit. If RNG is generated internally, project risks ( $R \& D$, generation and transport) are wholly born by the firm. Some of this risk could be mitigated using creative capital financing with creditors [62]. The absence of an approved methodology for the process in the province-and more generally regulation uncertainty-is another type of risk that must be accounted for $[46,63]$.

\subsubsection{Afforestation/Reforestation}

Once the technological in-house GHG reduction solutions to achieve net-zero for the Énergie Saguenay project have been exhausted, one can look at the possibility for large-scale tree plantations to capture the remainder of the produced $\mathrm{CO}_{2}$ emissions (Table S3). Afforestation (per convention: whereby trees are planted on $\leq 25 \%$ canopy covered land since $1990[64,65]$ ) is a confirmed efficient low-cost tool in climate change mitigation $[65,66]$. Estimates of its global mitigation potential vary, ranging from $\sim 3.2 \mathrm{Gt} \mathrm{CO}_{2}$-eq in 2018 [67] to a potential of $42-205 \mathrm{Gt} \mathrm{CO}_{2}$-eq, if deforestation was stopped and all available/suitable lands were covered by mature forests $[66,68]$, being mindful of land competition and conversion, to avoid adverse consequences on other sustainable development goals $[69,70]$.

Afforestation/reforestation are recognized activities that can generate carbon offset credits in the Kyoto Protocol, strictly following recognized methodologies [33,43,64]. Two types of forest credits can be obtained, ex-ante, where the credits are determined based on future $\mathrm{CO}_{2}$ capture by the planted trees, and ex-post, calculated by the actual $\mathrm{CO}_{2}$-stock net growth [43]. Models, such as CBM-CFS3 in Canada [71], evaluate carbon stocks based on tree species, location and growth yield. Serialized forest carbon credits are available to the Énergie Saguenay project through the WCI but not with the SPEDE as the Quebec government has no approved afforestation/reforestation methodology [31]. If GNL Québec wanted to create their own afforestation carbon credits in Quebec (as is their intention, pers. comm.), for now, these would have to be on voluntary markets unless regulations changed.

In the Province of Quebec, 1.7 million hectares of public land are suitable boreal open woodlands [72], of which only $10 \%$ is within $5 \mathrm{~km}$ of existing roads [73]. Private lands, mainly fallow lands (that were clear-cut for agriculture before 1990 [33]) represent only 3000 ha in the SaguenayLac-St-Jean area (Ministère de l'Agriculture, des Pêcheries et de l'Alimentation du Québec-MAPAQ, pers. comm.). Either for public or private land, authorizations must be granted by the relevant ministry (Quebec's Ministère des Forêts, de la Faune et des Parcs-MFFP and MAPAQ, respectively), and key requirements of plantations' additionality (the project sequesters more carbon than the "business as usual" scenario), permanence (must be maintained for 100 years) and non-leakage (must not cause a displacement of GHG emissions) must be observed $([33,43])$. In addition, carbon credit ownership would have to be determined, as they usually belong to the proprietor of the land (be it government or farmers). Lastly, as the intent is for the Énergie Saguenay project to be carbon neutral starting 2025, plantations should begin promptly as the process to get forestry carbon credits is very involved (see [74] for example) and trees of the boreal forest are slow growing, capturing carbon accordingly (e.g., net sequestration rate of $4 \mathrm{t} \mathrm{CO}_{2}$-eq ha ${ }^{-1} \mathrm{y}^{-1}$ for planted black spruce (Picea mariana (Mill.) 
B.S.P.) [75]). At least 27 years will, therefore, be necessary for the first ex-post verified credits to be available to offset the plant's GHG emissions, within the 25-50-year facility operational life expectancy $[25,75]$. Acquiring existing older plantations admissible as forest carbon credits could cut down waiting time, but the number of hectares necessary to capture the remaining $\mathrm{CO}_{2}$-eq after reduction every year remains an issue. Thus, regardless of the tree species and its growth rate, it is not possible under present rules to offset a significant year-to-year portion of the GHG emissions using only afforestation projects in the Province of Quebec.

The global GHG mitigation potential of afforestation is estimated between $0.2-13.8 \mathrm{Gt} \mathrm{CO}_{2}$-eq y ${ }^{-1}$ in 2030 at costs of up to $100 \mathrm{USDt}^{-1} \mathrm{CO}_{2}$-eq [76]. Mitigation potentials of $0.01-1.45$ and $0.11-9.5 \mathrm{Gt} \mathrm{CO}_{2}$-eq y ${ }^{-1}$ in 2030 can also be achieved at lower costs up to 20 and $50 \mathrm{USD} \mathrm{t}^{-1} \mathrm{CO}_{2}$-eq, respectively [76]. Using provincial data [77], we estimate that afforestation cost in Quebec would be $2-15 \mathrm{CAD} \mathrm{t}^{-1} \mathrm{CO}_{2}$-eq for public land and 2-13 $\mathrm{CAD} \mathrm{t}^{-1} \mathrm{CO}_{2}$-eq for private land. Estimates are slightly higher when using American data [78]. While afforestation cost makes it an interesting option, issues related to the access to the land and offset ownership remains to be addressed. Transaction costs [79] may be significant, especially for transactions involving private lands. Uncertainty related to offsets from afforestation comes hazard during tree growth (pests, wildfires) [80,81]. While these are easily observed ex-post, they must be accounted for at the beginning of the project; a riskier environment decreases the expected benefits associated with the option [82]. Given the regulatory and land availability constraints of offsets generated by afforestation, this option is to be used in conjunction with other methods.

\subsubsection{Offsets}

Once solutions to decrease GHG emissions or generate carbon credits have been exhausted, GNL Québec will need to acquire available offsets. Their use can amount to no more than $8 \%$ to meet SPEDE's regulatory compliance to, foremost, encourage reductions [31]. Five approved methodologies are in effect in Quebec, generating 813,763 $\mathrm{tCO}_{2}$-eq available credits (in May 2020 [31]). After complying, carbon credits can be purchased on voluntary markets, usually through a broker, to achieve carbon neutrality. There are many different standards, methodologies and protocols used in voluntary carbon markets over the world (e.g., UN's Clean Development Mechanism, American Carbon registry, CSA group registries, etc.) and the types of GHG reduction projects realized, across all sectors, vary tremendously with associated varying co-benefits $[64,83,84]$. To help in the selection of projects/carbon credits, priorities should be determined and weighed before performing a multiple-criteria decision analysis. For example, GNL Québec may choose to mitigate their GHG emissions via credits generated in the province of their operations or favor specific SDG goals (e.g., reduce poverty, offer clean energy, increase biodiversity, etc.). In Quebec, projects are concentrated in the forestry, energy efficiency and waste disposal sectors (e.g., [85]).

Used with the other options explained above, carbon offsets serve as an outside option for GNL Québec. Provided no supply constraint comes into play, the market price for carbon offsets sets an upper bound to the cost of other abatement technology. Of course, other project-specific attributes will impact the choice of offsets the firm chooses, but that reasoning also applies to the general problem of choosing a portfolio of options. It is up to the firm to determine its priorities in achieving carbon neutrality. This is especially true as some options may be associated with externalities that must be priced and included in the project analyses.

One of the main interesting features of offsets is to link the offset price to allowance price. The floor price for allowances is established by the Province of Quebec [32]. With increases in the minimum price pegged to inflation, it provides a benchmark on which to evaluate the future abatement costs of the other options. However, offset and allowance prices are not necessarily perfectly correlated, with offsets being consistently cheaper than allowances in the European Trading Scheme (ETS). Some of this discrepancy is to be expected, as market linkages should lower the cost of reducing GHG emissions, but no convergence is to be expected given the inherent limits to the use of offsets in achieving 
regulatory compliance [31]. Transaction costs [86] and different reaction to market fundamentals [87], as well as uncertainty, have been proposed to explain the gap [88].

\subsubsection{Environmental and Social Implications of the Potential Solutions}

For an LNG plant, achieving carbon neutrality from the get-go may have environmental and social implications other than climate change mitigation. The net-zero commitment is a voluntary pledge that implies investments and projects outside the boundaries of the Énergie Saguenay project itself. Therefore, this pledge is expected to have residual impacts other than those described in the environmental impact statement $[27,28]$.

It is currently impossible to quantify potential impact displacement of being carbon neutral for Énergie Saguenay project. To do so, good practices would necessitate LCA studies as requested by ISO 14040 standard [89]. As the firm does not have a formalized planning to achieve its pledge from the get-go, and for the lifespan of the LNG plant, the available information is not sufficient. Thus, it is only possible at this stage to identify for each category potential implications and sensitive environmental components that may be impacted. For example, CCU, depending on the technology and products used for capture, distance to user, chemical processes and end use, may have implications in energy consumption, waste disposal, air and water pollutant emissions, land-use conflicts as well as employment. RNG, depending on the technology, may have implications on land-use change, aboriginal rights, water and biodiversity, air and soil quality depending on feedstock sustainability from agriculture or forestry. Afforestation may impact biodiversity, water cycle, land-use conflicts and soil conservation and restoration (e.g., carbon sequestration, limiting erosion). Offsets credits quality depends on the program (e.g., Verified Carbon Standard or Gold Standard) and location of projects. Ancillary environmental and social benefits may be anticipated but they would differ for renewable energy, industrial processes replacement, wetland restoration, agriculture or forestry credits in developed or developing countries.

In these conditions, it would be possible to assess net environmental and social benefits or impact displacements only after the firm would have determined its portfolio of measures to realize its pledge for a given year. However, as a general rule, as the governments of Quebec and Canada are committed to sustainable development and well-regulated for environmental and social protection, measures selected by the firm that can benefit local projects or offsets would be easier to document for this purpose and may be considered preferable overall.

\subsection{Economic Perspective}

Despite that offsets can bring environmental and social co-benefits, from an environmental perspective, it is always better to avoid emitting GHG [33,43]. Thus, the priority for the company should be at first GHG source reduction with CCU, waste heat recovery and RNG. Offsets by afforestation and carbon credits are the last choice solution. However, in reality, climate change is the perfect example of a market failure. The absence of a supranational authority to deal with the challenge means international cooperation is needed. However, the lack of coordination among countries leads to underfunding of clean initiatives.

To help solve the issues, economists long have promoted market options to ensure that private incentives are aligned with the public good: carbon pricing, either using cap-and-trade, a Pigovian tax or mix of tools allows for consumers and firm to internalize the environmental cost of GHG emissions. By pricing GHG, incentives are back in place to allow agents internalize the negative environmental externalities. With high GHG footprint goods become relatively pricier and agents substitute away from them. A lack of suitable substitutes, as indicated by low price elasticity of demand for high GHG footprint goods, will have to be associated with higher pricing to induce the necessary decrease to achieve an emission reduction target.

There remains some uncertainty surrounding the introduction of a new large emitter in Quebec. While the provincial emission reduction target is not supposed to be affected, new emitters are not 
clearly accounted for in governmental GHG predictions, especially if they are to get free allowances. Depending on its abatement cost structure, a large emitter may have a non-trivial impact on auctioned allowance prices.

Since every emission is to be backed by an emission permit (allowance or offset), the firm faces a choice: lower its emission levels so that fewer permits are required or buy emission permits. When bidding for the auctioned allowances, an emitter's bid must reflect its underlying marginal abatement cost. If the final auctioned price is higher than a firm's bid, then it is more economical to abate emissions by adapting its manufacturing processes than to buy an offset.

For a large emitter in a new industry, there are regulatory uncertainties as to whether its emissions will be partially or fully covered by the SPEDE. A firm interested in becoming carbon neutral, with net-zero emissions, has to go above-and-beyond and find ways to compensate all its emissions. The nature of the problem is the same as in the compliance market: in equilibrium, the firm will reduce in-house emissions up to the point at which its marginal abatement cost equals the offset cost. A firm internal abatement costs are determined by studying all technically feasible options and by finding the associated costs and risks. Only then can the firm know more about its willingness to pay for allowances-and offsets. To find these practical options, the firm may get clues from top-down approaches, but as these generally lack the technical details necessary for small-scale decision-making, they will narrow down options using bottom-up approaches and internal and external resources. The final choice of abatement instruments requires careful financial analysis of abatement costs (investments and financing), risks and blend-in knowledge of the offset and allowance markets. In this context, a portfolio approach to abatement technology will be the key to minimize financial risk associated with becoming carbon neutral.

\section{Conclusions}

This study shows how a new major industrial GHG emitter starting its operation in 2025 in Quebec, Canada, could be carbon neutral for its Scope 1 emissions by compiling a net-zero carbon footprint from the get-go; in accordance with the Paris Agreement plan to stabilize the climate at $+1.5^{\circ} \mathrm{C}$ by the end of the century. The potential for GHG emission reduction and capture worldwide provide enough opportunities to achieve the $-45 \%$ decrease by the 2030 objective. To be carbon neutral, the Énergie Saguenay project, led by GNL Québec, must put in place an array of cohesive strategies. Industrial ecology solutions with the sale of high-quality residual $\mathrm{CO}_{2}$ and low carbon footprint heat geared towards other neighbored industries shows good potential. Replacing NG by RNG produced by pyrolysis of forestry residues also has a high potential, but technological hurdles remain as well as supply challenges. This solution may only be truly available past 2030 and cover only part of the reduction needs. Afforestation by the company is a good solution but with an effective timeframe of 2050 and is limited in actual conditions under Quebec regulations. Buying carbon offsets is essential, at least at the beginning of the liquefaction facility operations. Therefore, these options are all practically and economically feasible for GNL Québec to be carbon neutral although uncertainties remain. In this context, adopting a portfolio approach aligned with the evolution of the compliance and voluntary carbon markets is the most suitable approach to minimize the environmental and economic risks and ensure the success of the carbon neutrality objective. However, the success of maintaining this pledge over the lifespan of the LNG plant will depend on the firm willingness and economic constraints.

Supplementary Materials: The following are available online at http://www.mdpi.com/2073-4433/11/8/810/s1, Table S1: References of the literature review performed on credible means to reduce greenhouse gas emissions and reach carbon neutrality in the energy sector. Table S2: References of the literature review performed on credible means to reduce greenhouse gas emissions and reach carbon neutrality in the agriculture sector. Table S3: References of the literature review performed on credible means to reduce greenhouse gas emissions and reach carbon neutrality in the forest sector. Table S4: References of the literature review performed on credible means to reduce greenhouse gas emissions and reach carbon neutrality in the building sector. Table S5: References of the literature review performed on credible means to reduce greenhouse gas emissions and reach carbon neutrality in the transport sector. Table S6: References of the literature review performed on credible means to reduce greenhouse gas emissions and reach carbon neutrality in the industry sector. Table S7: References of the 
literature review performed on credible means to reduce greenhouse gas emissions and reach carbon neutrality in geoengineering. Table S8: References of the literature review performed on credible means to reduce greenhouse gas emissions and reach carbon neutrality in the sector of $\mathrm{CO}_{2}$ utilization and waste heat recovery. Table S9: References of the literature review performed on the production and use of renewable natural gas as a credible mean to reduce greenhouse gas emissions and reach carbon neutrality. Table S10: References of the literature review performed on credible means to reduce greenhouse gas emissions and reach carbon neutrality regarding the economic feasibility.

Author Contributions: Conceptualization, P.F., S.B., R.M.C., H.C., P.-L.D. and C.V.; methodology, P.F., R.M.C., H.C., P.-L.D. and C.V.; validation, P.F., S.B., R.M.C., H.C., P.-L.D. and C.V.; formal analysis, P.F., R.M.C., H.C., P.-L.D. and C.V.; investigation, P.F., S.B., R.M.C., H.C., P.-L.D. and C.V.; resources, C.V.; data curation, P.F., R.M.C., H.C., P.-L.D. and C.V.; writing-original draft preparation, S.B.; writing-review and editing, P.F., S.B., R.M.C., H.C., P.-L.D. and C.V.; visualization, S.B.; supervision, P.F., S.B. and C.V.; project administration, C.V.; funding acquisition, C.V. All authors have read and agreed to the published version of the manuscript.

Funding: This research was funded by the Chaire en éco-conseil, Université du Québec à Chicoutimi.

Acknowledgments: We thank Olivier Fradette from Carbone boréal (Université du Québec à Chicoutimi) for his modeling input in the section on afforestation/reforestation and GNL Québec for the right to use data for this case study.

Conflicts of Interest: The authors declare no conflict of interest.

\section{References}

1. United Nations. Paris Agreement; United Nations: New York, NY, USA, 2015.

2. IPCC (Intergovernmental Panel on Climate Change). Global Warming of $1.5^{\circ} \mathrm{C}$. An IPCC Special Report on the Impacts of Global Warming of $1.5^{\circ} \mathrm{C}$ above Pre-Industrial Levels and Related Global Greenhouse Gas Emission Pathways, in the Context of Strengthening the Global Response to the Threat of Climate Change, Sustainable Development, and Efforts to Eradicate Poverty; Intergovernmental Panel on Climate Change: Geneva, Switzerland, 2018.

3. UNEP (United Nations Environment Programme). Emissions Gap Report 2018; United Nations Environment Programme: Nairobi, Kenya, 2018.

4. UNEP. Emissions Gap Report 2019; United Nations Environment Programme: Nairobi, Kenya, 2019.

5. Stern, P.C.; Sovacool, B.K.; Dietz, T. Towards a science of climate and energy choices. Nat. Clim. Chang. 2016, 6, 547-555. [CrossRef]

6. Arnette, A.N. Renewable energy and carbon capture and sequestration for a reduced carbon energy plan: An optimization model. Renew. Sustain. Energy Rev. 2017, 70, 254-265. [CrossRef]

7. IRENA (International Renewable Energy Agency). REmap: Roadmap for A Renewable Energy Future, 2016 ed.; International Renewable Energy Agency: Abu Dhabi, UAE, 2016.

8. UNEP. The Emissions Gap Report 2017; United Nations Environment Programme: Nairobi, Kenya, 2017.

9. Styring, P.; de Coninck, H.; Reith, H.; Armstrong, K. Carbon Capture and Utilisation in the Green Economy Using $\mathrm{CO}_{2}$ to Manufacture Fuel, Chemicals and Materials; The Centre for Low Carbon Futures 2011 and CO2Chem Publishing: New York, NY, USA, 2011.

10. Youinou, G.J. Powering sustainable low-carbon economies: Some facts and figures. Renew. Sustain. Energy Rev. 2016, 53, 1626-1633. [CrossRef]

11. Mousseau, N.; Villeneuve, C. Pour une approche stratégique pour la transition énergétique et la lutte aux changements climatiques. In Le Québec Économique 8: Le Développement Durable à L'ère des Changements Climatiques; Joanis, M., Sinclair-Desgagné, B., Eds.; Les Presses de l’Université Laval et CIRANO: Montreal, QC, Canada, 2019; pp. 313-340.

12. United Nations Framework Convention on Climate Change, UNFCCC. Report of the Conference of the Parties on Its Twenty-Fourth Session, Held in Katowice from 2 to 15 December 2018. Part One: Proceedings. Part Two: Action Taken by the Conference of the Parties at its Twenty-Fourth Session; United Nations: New York, NY, USA, 2019 ; p. 27.

13. UNEP. Towards A Green Economy: Pathways to Sustainable Development and Poverty Eradication-A Synthesis for Policy Makers; UNEP: Nairobi, Kenya, 2011; p. 45.

14. RE100. Available online: http://there100.org/ (accessed on 23 August 2019).

15. United Nations Global Compact, Science Based Targets Initiative (SBTi) and the We Mean Business Coalition. 87 Major Companies Lead the Way Towards a $1.5^{\circ} \mathrm{C}$ Future at UN Climate Action Summit. Available online: https://www.unglobalcompact.org/news/4476-09-21-2019 (accessed on 3 April 2020). 
16. United Nations Environment Programme Finance Initiative, UNEP. About United Nations Environment Programme Finance Initiative. Available online: https://www.unepfi.org/about/ (accessed on 3 April 2020).

17. Höhne, N.; den Elzen, M.; Rogelj, J.; Metz, B.; Fransen, T.; Kuramochi, T.; Olhoff, A.; Alcamo, J.; Winkler, H.; $\mathrm{Fu}, \mathrm{S}$.; et al. Emissions: World has four times the work or one-third of the time. Nature 2020, 579, 25-28. [CrossRef] [PubMed]

18. Science Based Targets. Science Based Targets Initiative. Available online: https://sciencebasedtargets.org/ about-the-science-based-targets-initiative/ (accessed on 1 April 2020).

19. Bataille, C.; Åhman, M.; Neuhoff, K.; Nilsson, L.J.; Fischedick, M.; Lechtenböhmer, S.; Solano-Rodriquez, B.; Denis-Ryan, A.; Stiebert, S.; Waisman, H.; et al. A review of technology and policy deep decarbonization pathway options for making energy-intensive industry production consistent with the Paris Agreement. J. Clean. Prod. 2018, 187, 960-973. [CrossRef]

20. Rogelj, J.; Huppmann, D.; Krey, V.; Riahi, K.; Clarke, L.; Gidden, M.; Nicholls, Z.; Meinshausen, M. A new scenario logic for the Paris Agreement long-term temperature goal. Nature 2019, 573, 357-363. [CrossRef]

21. Sump, F.; Yi, S. Different Reasons for Different Responses: A Review of Incumbents' Adaptation in CarbonIntensive Industries. Organ. Environ. 2020. [CrossRef]

22. Falter, W.; Langer, A.; Wesche, F.; Weze, S. Decarbonization strategies in converging chemical and energy markets. J. Bus. Chem. 2020, 17, 20-40. [CrossRef]

23. Pilpola, S.; Arabzadeh, V.; Mikkola, J.; Lund, P.D. Analyzing National and Local Pathways to CarbonNeutrality from Technology, Emissions, and Resilience Perspectives-Case of Finland. Energies 2019, 12, 949. [CrossRef]

24. Detz, R.J.; van der Zwaan, B. Transitioning towards negative $\mathrm{CO}_{2}$ emissions. Energy Policy 2019, 133, 110938. [CrossRef]

25. GNL Québec. Énergie Saguenay. Available online: https://energiesaguenay.com/en/ (accessed on 4 May 2020).

26. Gazoduq. Gazoduq Project. Detailed Project Description. January 2020. Submitted to: The Impact Assessment Agency of Canada; Gazoduq Inc.: Montreal, QC, Canada, 2020.

27. WSP. Projet Énergie Saguenay. Étude D'impact Environnemental. Version Finale; WSP Canada Inc.: Quebec, QC, Canada, 2019; p. 1132.

28. WSP. Énergie Saguenay Project. Summary of the Environmental Impact Assessment; WSP Canada Inc.: Quebec, QC, Canada, 2019; p. 70.

29. Bureau D'audiences Publiques sur L'environnement, BAPE. Projet de Construction d'un Complexe de Liquéfaction de Gaz Naturel À Saguenay. Available online: https://www.bape.gouv.qc.ca/fr/dossiers/projetcomplexe-liquefaction-gaz-naturel-saguenay/ (accessed on 23 July 2020).

30. Ministère de l'Environnement et de la Lutte contre les Changements Climatiques, MELCC. Environmental Assessment in Southern Quebec. Available online: http://www.environnement.gouv.qc.ca/evaluations/ procedure-en.htm\#process (accessed on 23 July 2020).

31. In MELCC; The Carbon Market, A Green Economy Growth Tool! Available online: http://www.environnement. gouv.qc.ca/changementsclimatiques/marche-carbone_en.asp (accessed on 14 April 2020).

32. Gouvernment of Quebec. Regulation Respecting A Cap-and-Trade System for Greenhouse Gas Emission Allowances; Chapitre Q-2, r. 46.1; Environment Quality Act, Gouvernment of Quebec, Eds.; Gouvernment of Quebec: Quebec City, QC, Canada, 2020.

33. World Business Council for Sustainable Development and the World Resources Institute, WBCSD/WRI. The Greenhouse Gas Protocol: A Corporate Accounting and Reporting Standard, Revised ed.; WBCSD: Geneva, Switzerland; WRI: Washington, DC, USA, 2004; p. 114.

34. Wernet, G.; Bauer, C.; Steubing, B.; Reinhard, J.; Moreno-Ruiz, E.; Weidema, B. The ecoinvent database version 3 (part I): Overview and methodology. Int. J. Life Cycle Assess. 2016, 21, 1218-1230. [CrossRef]

35. Global CCS Institute. Global Status of CCS 2019. Targeting Climate Change; Global CCS Institute: Melbourne, Australia, 2019; p. 85.

36. $\mathrm{CO}_{2}$ Sciences and the Global $\mathrm{CO}_{2}$ Initiative. Global Roadmap for Implementing $\mathrm{CO}_{2}$ Utilization; The Global CO2 Initiative: Ann Arbor, MI, USA, 2016.

37. Rahman, F.A.; Aziz, M.M.A.; Saidur, R.; Abu Bakar, W.A.W.; Hainin, M.R.; Putrajaya, R.; Hassan, N.A. Pollution to solution: Capture and sequestration of carbon dioxide $\left(\mathrm{CO}_{2}\right)$ and its utilization as a renewable energy source for a sustainable future. Renew. Sustain. Energy Rev. 2017, 71, 112-126. [CrossRef] 
38. Rudin, S.N.F.M.; Muis, Z.; Hashim, H.; Ho, W.S. Overview of carbon reduction, capture, utilization and storage: Development of new framework. Chem. Eng. Trans. 2017, 56, 649-654. [CrossRef]

39. IPCC. IPCC Special Report on Carbon Dioxide Capture and Storage. Prepared by Working Group III of the Intergovernmental Panel on Climate Change; Cambridge University Press: Cambridge, UK; New York, NY, USA, 2005; p. 442.

40. Gouvernment of Quebec. Regulation Respecting Mandatory Reporting of Certain Emissions of Contaminants into the Atmosphere; Chapter Q-2, r. 15; Gouvernment of Quebec, Ed.; Gouvernment of Quebec: Québec, QC, Canada, 2020.

41. Natural Resources Canada. Waste Heat Recovery and Upgrading. Available online: https://doi.org/10.1016/j. apenergy.2016.06.147 (accessed on 21 April 2020).

42. Government of Alberta. Alberta Emission Offset System. Available online: https://www.alberta.ca/albertaemission-offset-system.aspx (accessed on 5 May 2020).

43. WBCSD/WRI. The Greenhouse Gas Protocol. The GHG Protocol for Project Accounting; WBCSD: Geneva, Switzerland; WRI: Washington, DC, USA, 2005; p. 144.

44. Rajhansa, K.; Al Horr, Y. Role of Regional Carbon Markets in Article 6.2 of Paris Agreement; Global Carbon Council: Aldafna, Doha, Qatar, 2019.

45. Chalmers, H.; Leach, M.; Lucquiaud, M.; Gibbins, J. Valuing flexible operation of power plants with $\mathrm{CO}_{2}$ capture. Energy Procedia 2009, 1, 4289-4296. [CrossRef]

46. Marcus, A.; Aragon-Correa, J.A.; Pinkse, J. Firms, Regulatory Uncertainty, and the Natural Environment. Calif. Manag. Rev. 2011, 54, 5-16. [CrossRef]

47. Herzog, H.J. The economics of $\mathrm{CO}_{2}$ separation and capture. Technol. Elmsf. J. Frankl. Inst. J. Sci. Serv. Legis. Regul. Judic. Syst. 2000, 7, 13-24.

48. International Association of Oil and Gas Producers, IOGP. The Potential for CCS and CCU in Europe. Report to the Thirty Second Meeting of the European Gas Regulatory Forum 5-6 June 2019; International Association of Oil and Gas Producers: London, UK, 2019.

49. European Commission. CASE M.8480-PRAXAIR/LINDE. MERGER PROCEDURE REGULATION (EC) 139/2004. Article 8(2) Regulation (EC) 139/2004; European Commission: Brussels, Belgium, 2018.

50. Centre International de Référence sur le Cycle de vie des Produits Procédés et Services, CIRAIG. Rapport Technique. Répartition des Émissions de GES du Cycle de vie Selon la Responasbilité de L'émetteur; CIRAIG: Montreal, QC, Canada, 2020.

51. IPCC. Climate Change 2014: Mitigation of Climate Change. Contribution of Working Group III to the Fifth Assessment Report of the Intergovernmental Panel on Climate Change; Cambridge University Press: Cambridge, UK; New York, NY, USA, 2014.

52. Ranius, T.; Hämäläinen, A.; Egnell, G.; Olsson, B.; Eklöf, K.; Stendahl, J.; Rudolphi, J.; Sténs, A.; Felton, A. The effects of logging residue extraction for energy on ecosystem services and biodiversity: A synthesis. J. Environ. Manag. 2018, 209, 409-425. [CrossRef]

53. Ho, D.P.; Ngo, H.H.; Guo, W. A mini review on renewable sources for biofuel. Bioresour. Technol. 2014, 169, 742-749. [CrossRef]

54. Aviseo Conseil. La Filière de Production de Gaz Naturel Renouvelable au Québec. Impacts Économiques À L'horizon 2030 et Contribution À L'économie Circulaire; Aviseo Conseil: Montreal, QC, Canada, 2019.

55. Biochar Boréalis. Biochar Boréalis Dans le Cadre de L'événement: Défis Industriels et Environnementaux de la Filière du Biochar au Québec. Available online: https://cribiq.qc.ca/content/file/filemanager/\%C3\% 89v\%C3\%A8nements/BIOCHAR/Pr\%C3\%A9sentations/Andr\%C3\%A9\%20Benoit-\%20Biochar\%20Bor\% C3\%A9alis.pdf (accessed on 31 July 2019).

56. WSP and Deloitte. Production Québécoise de Gaz Naturel Renouvelable (GNR): Un Levier Pour la Transition Énergétique Évaluation du Potentiel Technico-Économique au Québec (2018-2030); WSP Canada Inc.: Montreal, QC, Canada; Deloitte S.E.N.C.R.L./s.r.l.: Toronton, ON, Canada, 2018.

57. Alberta Environment. Quantification Protocol for Diversion of Biomass to Energy from Biomass Combustion Facilities; Version 1.0; Environmental Monitoring and Evaluation: Edmonton, AB, Canada, 2007.

58. Government of Alberta. Quantification Protocol for Energy Generation from the Combustion of Biomass Waste; Version 2.0; Alberta Environment and Sustainable Resource Development: Edmonton, AB, Canada, 2014.

59. Government of British Columbia. Greenhouse Gas Emission Offset Projects. Available online: https://www2. gov.bc.ca/gov/content/environment/climate-change/industry/offset-projects (accessed on 13 May 2020). 
60. Gouvernment of Quebec. Regulation Respecting the Quantity of Renewable Natural Gas to be Delivered by a Distributor. Act Respecting the Régie de L'énergie; Chapter R-6.01, s. 112, 1st. Par., Subpar. 4; Gouvernment of Quebec, Ed.; Gouvernment of Quebec: Quebec City, QC, Canada, 2020.

61. Canadian Council of Forest Ministers. National Forestry Database. Wood supply. Available online: http://nfdp.ccfm.org/en/data/woodsupply.php (accessed on 20 May 2020).

62. Parker, N.; Williams, R.; Dominguez-Faus, R.; Scheitrum, D. Renewable natural gas in California: An assessment of the technical and economic potential. Energy Policy 2017, 111, 235-245. [CrossRef]

63. Campbell, J.; Herremans, I.M.; Kleffner, A. Barriers to achieving additionality in carbon offsets: A regulatory risk perspective. J. Environ. Plan. Manag. 2018, 61, 2570-2589. [CrossRef]

64. UNFCCC. Afforestation and Reforestation Projects under the Clean Development Mechanism: A Reference Manual; Climate Change Secretariat (UNFCCC): Bonn, Germany, 2013; p. 76.

65. IPCC. Forestry. In Climate Change 2007: Mitigation. Contribution of Working Group III to the Fourth Assessment Report of the Intergovernmental Panel on Climate Change; IPCC: Geneva, Switzerland, 2007; pp. 541-584.

66. Bastin, J.-F.; Finegold, Y.; Garcia, C.; Mollicone, D.; Rezende, M.; Routh, D.; Zohner, C.M.; Crowther, T.W. The global tree restoration potential. Science 2019, 365, 76-79. [CrossRef] [PubMed]

67. Le Quéré, C.; Andrew, R.M.; Friedlingstein, P.; Sitch, S.; Hauck, J.; Pongratz, J.; Pickers, P.A.; Korsbakken, J.I.; Peters, G.P.; Canadell, J.G.; et al. Global Carbon Budget 2018. Earth Syst. Sci. Data 2018, 10, 2141-2194. [CrossRef]

68. Veldman, J.W.; Aleman, J.C.; Alvarado, S.T.; Anderson, T.M.; Archibald, S.; Bond, W.J.; Boutton, T.W.; Buchmann, N.; Buisson, E.; Canadell, J.G.; et al. Comment on "The global tree restoration potential". Science 2019, 366, eaay7976. [CrossRef] [PubMed]

69. IPCC. Climate Change and Land. An IPCC Special Report on Climate Change, Desertification, Land Degradation, Sustainable Land Management, Food Security, and Greenhouse Gas Fluxes in Terrestrial Ecosystems; Intergovernmental Panel on Climate Change: Geneva, Switzerland, 2019.

70. Morecroft, M.D.; Duffield, S.; Harley, M.; Pearce-Higgins, J.W.; Stevens, N.; Watts, O.; Whitaker, J. Measuring the success of climate change adaptation and mitigation in terrestrial ecosystems. Science 2019, 366, eaaw9256. [CrossRef]

71. Kurz, W.A.; Dymond, C.C.; White, T.M.; Stinson, G.; Shaw, C.H.; Rampley, G.J.; Smyth, C.; Simpson, B.N.; Neilson, E.T.; Trofymow, J.A.; et al. CBM-CFS3: A model of carbon-dynamics in forestry and land-use change implementing IPCC standards. Ecol. Model. 2009, 220, 480-504. [CrossRef]

72. Ministère des Forêts, de la Faune et des Parcs, MFFP. Inventaire Écoforestier. Available online: https: //mffp.gouv.qc.ca/les-forets/inventaire-ecoforestier/ (accessed on 24 August 2019).

73. Plante, F. Évaluation des Superficies Potentielles de Remise en Production des Strates Mal Régénérées de la Région 02. Rapport de L'étape 3; Les Entreprises Gauthier, Parent, Ltée, pour le compte du Bureau régional 02 du Ministère des Ressources naturelles; Gouvernement du Québec: Quebec City, QC, Canada, 2003.

74. Tree Canada. Tree Canada Afforestaiton and Reforestation Protocol; Version 2.0; Tree Canada: Ottawa, ON, Cananda, 2015; p. 62.

75. Gaboury, S.; Boucher, J.-F.; Villeneuve, C.; Lord, D.; Gagnon, R. Estimating the net carbon balance of boreal open woodland afforestation: A case-study in Québec's closed-crown boreal forest. For. Ecol. Manag. 2009, 257, 483-494. [CrossRef]

76. Smith, P.; Bustamante, M.; Ahammad, H.; Clark, H.; Dong, H.; Elsiddig, E.A.; Haberl, H.; Harper, R.; House, J.; Jafari, M.; et al. Agriculture, Forestry and Other Land Use (AFOLU). In Climate Change 2014: Mitigation of Climate Change. Contribution of Working Group III to the Fifth Assessment Report of the Intergovernmental Panel on Climate Change; Edenhofer, O., Pichs-Madruga, R., Sokona, Y., Farahani, E., Kadner, S., Seyboth, K., Adler, A., Baum, I., Brunner, S., Eickemeier, P., et al., Eds.; Cambridge University Press: Cambridge, UK; New York, NY, USA, 2014.

77. Bureau de Mise en Marché des Bois, BMMB. Analyse de Rentabilité Économique des Plantations D'Épinette Noire et Blanche et de Pin Gris; Gouvernement du Québec: Quebec City, QC, Canada, 2014.

78. Gorte, R.W. U.S. Tree Planting for Carbon Sequestration; Congressional Research Service: Washington, DC, USA, 2009.

79. Torres, A.B.; Marchant, R.; Lovett, J.C.; Smart, J.C.R.; Tipper, R. Analysis of the carbon sequestration costs of afforestation and reforestation agroforestry practices and the use of cost curves to evaluate their potential for implementation of climate change mitigation. Ecol. Econ. 2010, 69, 469-477. [CrossRef] 
80. Hurteau, M.D.; Hungate, B.A.; Koch, G.W. Accounting for risk in valuing forest carbon offsets. Carbon Balance Manag. 2009, 4, 1. [CrossRef]

81. Hurteau, M.D.; North, M. Carbon recovery rates following different wildfire risk mitigation treatments. For. Ecol. Manag. 2010, 260, 930-937. [CrossRef]

82. Chomitz, K. Evaluating Carbon Offsets from Forestry and Energy Projects (English); Policy, Research Working Paper no. WPS 2357; The World Bank: Washington, DC, USA, 2000.

83. Ecosystem Marketplace. State of the Voluntary Carbon Markets 2019. Available online: https://www.foresttrends.org/sovcm2019/ (accessed on 24 August 2019).

84. UNFCCC. Climate Neutral Now. Available online: https://unfccc.int/climate-action/climate-neutral-now (accessed on 24 August 2019).

85. Canadian Standards Association, CSA. GHG CleanProjects ${ }^{\circledR}$ Registry. Available online: https://www. csaregistries.ca/cleanprojects/index_e.cfm (accessed on 6 May 2020).

86. Trotignon, R. Combining cap-and-trade with offsets: Lessons from the EU-ETS. Clim. Policy 2012, 12, $273-287$. [CrossRef]

87. Nazifi, F. Modelling the price spread between EUA and CER carbon prices. Energy Policy 2013, 56, 434-445. [CrossRef]

88. Hintermann, B.; Gronwald, M. Linking with Uncertainty: The Relationship Between EU ETS Pollution Permits and Kyoto Offsets. Environ. Resour. Econ. 2019, 74, 761-784. [CrossRef]

89. International Organization for Standardization, ISO. ISO 14040:2006. Environmental Management-Life Cycle Assessment-Principles and Framework; International Organization for Standardization: Geneva, Switzerland, 2006.

(C) 2020 by the authors. Licensee MDPI, Basel, Switzerland. This article is an open access article distributed under the terms and conditions of the Creative Commons Attribution (CC BY) license (http://creativecommons.org/licenses/by/4.0/). 